\title{
Comparison of Morphology of Sorghum Grain to Resistance to Maize Weevil, Sitophilus zeamais
}

\author{
M. W. Pendleton*, E. A. Ellis*, F. M. Chitio**, and B. B. Pendleton** \\ * Microscopy and Imaging Center, Texas A\&M University, Biological Sciences Building Room \\ Number 119, Mail Stop 2257, College Station, TX. 77843-2257 \\ ** Division of Agriculture, West Texas A\&M University, Box 60998, Canyon, TX. 79016-0001
}

The maize weevil, Sitophilus zeamais Motschulsky, is one of most damaging insect pests of stored grain, including sorghum, Sorghum bicolor (L.) Moench [1]. Maize weevils infest kernels in the field, deposit eggs in stored kernels, and the larva feeds inside and damages the kernel. While the use of sorghum resistant to weevils is an alternative to insecticide, resistance to maize weevils in different sorghum genotypes has not been evaluated for more than 20 years. The first goal of this research was to evaluate the resistance of 20 genotypes of stored sorghum grain to maize weevil. The second goal was to examine the relationship between resistance to weevils and the morphology of the seed coat observed using light microscopy (LM) and scanning electron microscopy (SEM).

Three female and two male newly emerged maize weevils were put with $5 \mathrm{~g}$ of sorghum grain in each of 10 vials. Twenty genotypes of sorghum were used. Vials of each kind of sorghum were sequentially set up and evaluated every three weeks for a total of 105 days. Each day, each grain in the 10 vials of one kind of sorghum was evaluated for damage, numbers of live and dead weevil adults were counted, and the grain in each vial was weighed. A scale of 1-5 was used to score damage (Table 1). Sureno was the most resistant genotype, while SC630-11E11 was least resistant.

Before observation by SEM, a razor blade and a small hammer were used to split dry grains of 20 genotypes of sorghum. The split grains were exposed to osmium vapor and coated with goldpalladium using a Hummer sputter coater. The cross-section of the seed coat of each genotype of sorghum was observed by SEM using a JEOL JSM 6400 at $15 \mathrm{KeV}, 12-\mathrm{mm}$ working distance, and magnifications of 500-2000x (Figs. 1, 3). Small pieces of the seed coat of each sorghum were dried, fixed, and embedded in epoxy resin and sectioned for observation by LM using a Zeiss Axiophot compound light microscope at bright field magnifications of 100-600x (Figs. 2, 4).

The different genotypes of sorghum grains observed in cross-section with SEM and LM were very different in appearance (Figs. 1-4), and this difference is related to the resistance of each genotype to maize weevil. For example, the thickness of the seed coat of the most resistant sorghum (Sureno) was nearly twice as thick as the seed coat of the least resistant genotype (SC630-11E11).

\section{References}

[1] Teetes, G. L., and B. B. Pendleton, Insect pests of sorghum, pp. 443-495. In C. W. Smith and R. A. Frederikson (eds.), Sorghum: Origin, History, Technology, and Production. Wiley Series in Crop Science, New York, 2000.

[2] This research was supported in part by the Instituto Nacional de Investigacao Agronomica de Mozambique (INIA), the U.S. Agency for International Development in Mozambique, and by the International Sorghum and Millet Collaborative Research Support Program (INTSORMIL CRSP) sponsored by the U.S. Agency for International Development, under the terms of Grant No. LAGG-00-96-90009-00. 
TABLE 1. Mean total number of maize weevil adults per gram, damage, and weight loss ( \pm standard error of the mean) at 105 days after infestation of sorghum grain

\begin{tabular}{lccc}
\hline Sorghum & Total maize weevils/gram & Damage score & \% weight loss \\
\hline Sureno & $3.1 \pm 0.50 \mathrm{~g}$ & $1.5 \pm 0.10 \mathrm{i}$ & $0.8 \pm 0.07 \mathrm{j}$ \\
Sima & $1.7 \pm 0.66 \mathrm{~g}$ & $1.6 \pm 0.19 \mathrm{i}$ & $3.8 \pm 0.09 \mathrm{ij}$ \\
Macia & $2.8 \pm 1.17 \mathrm{~g}$ & $1.8 \pm 0.26 \mathrm{hi}$ & $5.4 \pm 0.18 \mathrm{~h}-\mathrm{j}$ \\
Malisor84-7-167 & $3.9 \pm 0.81 \mathrm{fg}$ & $1.7 \pm 0.14 \mathrm{hi}$ & $6.6 \pm 0.12 \mathrm{hi}$ \\
Tegemeo & $3.5 \pm 1.02 \mathrm{fg}$ & $2.0 \pm 0.20 \mathrm{~g}-\mathrm{I}$ & $8.2 \pm 0.14 \mathrm{~h}$ \\
ATx635 & $6.4 \pm 0.81 \mathrm{ef}$ & $2.3 \pm 0.15 \mathrm{f}-\mathrm{h}$ & $13.8 \pm 0.12 \mathrm{gh}$ \\
Malisor84-7-476 & $7.4 \pm 1.11 \mathrm{de}$ & $2.5 \pm 0.20 \mathrm{fg}$ & $15.2 \pm 0.16 \mathrm{~g}$ \\
Kuyuma & $7.3 \pm 1.75 \mathrm{de}$ & $2.7 \pm 0.24 \mathrm{ef}$ & $16.8 \pm 0.24 \mathrm{~g}$ \\
Tx2882 & $7.5 \pm 1.35 \mathrm{de}$ & $2.7 \pm 0.21 \mathrm{~d}-\mathrm{f}$ & $17.4 \pm 0.18 \mathrm{fg}$ \\
Segaolane & $8.6 \pm 0.94 \mathrm{de}$ & $2.8 \pm 0.27 \mathrm{c}-\mathrm{f}$ & $21.8 \pm 0.21 \mathrm{f}$ \\
B1 & $10.6 \pm 1.11 \mathrm{~b}-\mathrm{d}$ & $3.1 \pm 0.18 \mathrm{c}-\mathrm{e}$ & $27.2 \pm 0.16 \mathrm{e}-\mathrm{g}$ \\
RTx430-5451 & $10.1 \pm 0.81 \mathrm{~b}-\mathrm{d}$ & $3.3 \pm 0.12 \mathrm{~b}-\mathrm{d}$ & $27.4 \pm 0.17 \mathrm{~d}-\mathrm{f}$ \\
Tx2737 & $10.0 \pm 2.08 \mathrm{~b}-\mathrm{d}$ & $3.2 \pm 0.37 \mathrm{~b}-\mathrm{e}$ & $30.2 \pm 0.31 \mathrm{~d}-\mathrm{f}$ \\
RTx430-5362 & $10.5 \pm 1.31 \mathrm{~b}-\mathrm{d}$ & $3.4 \pm 0.24 \mathrm{a}-\mathrm{c}$ & $32.0 \pm 0.25 \mathrm{c}-\mathrm{e}$ \\
ATx623 & $10.4 \pm 1.31 \mathrm{~b}-\mathrm{d}$ & $3.2 \pm 0.20 \mathrm{~b}-\mathrm{e}$ & $32.2 \pm 0.23 \mathrm{~b}-\mathrm{e}$ \\
Tx2911 & $9.5 \pm 1.39 \mathrm{c}-\mathrm{e}$ & $3.4 \pm 0.33 \mathrm{a}-\mathrm{c}$ & $33.8 \pm 0.29 \mathrm{a}-\mathrm{d}$ \\
SRN39 & $12.9 \pm 1.49 \mathrm{ab}$ & $3.7 \pm 0.24 \mathrm{ab}$ & $35.8 \pm 0.22 \mathrm{a}-\mathrm{d}$ \\
ATx631 & $12.0 \pm 1.50 \mathrm{a}-\mathrm{c}$ & $3.9 \pm 0.21 \mathrm{a}$ & $37.2 \pm 0.25 \mathrm{a}-\mathrm{c}$ \\
CE151 & $14.2 \pm 0.95 \mathrm{a}$ & $4.0 \pm 0.15 \mathrm{a}$ & $43.4 \pm 0.14 \mathrm{ab}$ \\
SC630-11E11 & $12.1 \pm 1.01 \mathrm{a}-\mathrm{c}$ & $3.9 \pm 0.21 \mathrm{a}$ & $46.8 \pm 0.21 \mathrm{a}$ \\
Least Squares Deviation 3.351 & 0.615 & 0.547 \\
Means followed by the same letter in a column are not significantly different $(P<0.0001)$.
\end{tabular}

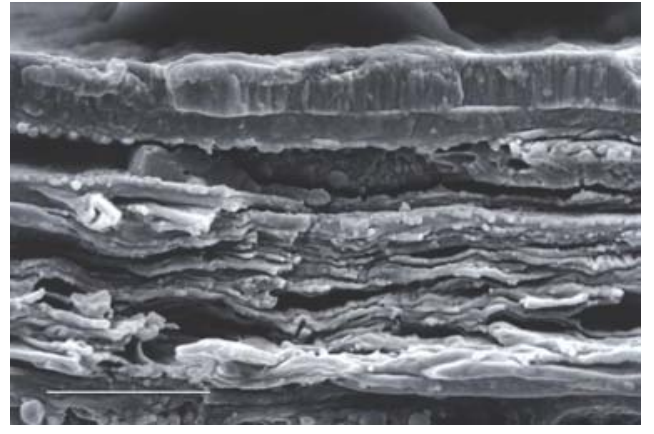

Fig. 1. SC630-11E11 (SEM). Scale bar $=10 \mu \mathrm{m}$.

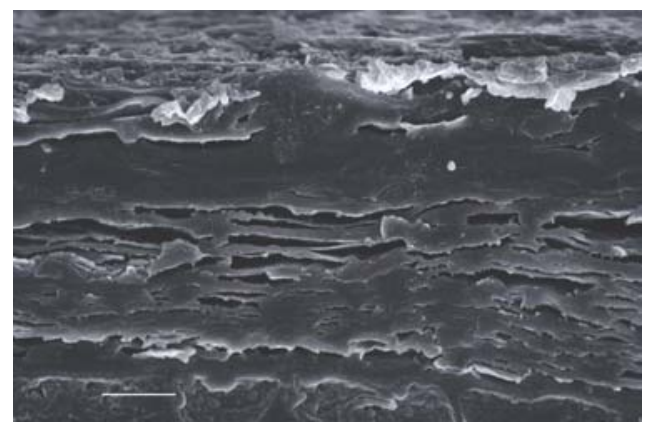

Fig. 3. Sureno (SEM). Scale bar $=15 \mu \mathrm{m}$.

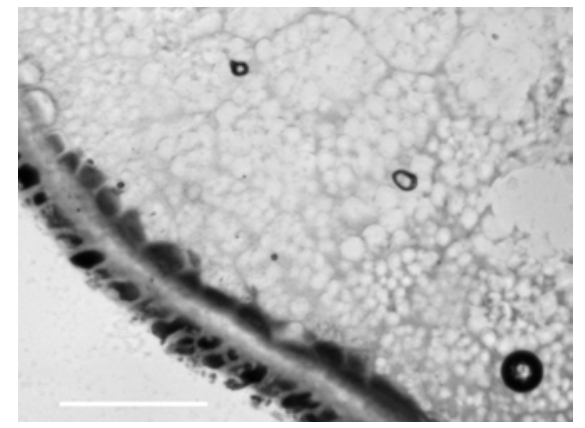

Fig. 2. SC630-11E11 (LM). Scale bar $=60 \mu \mathrm{m}$.

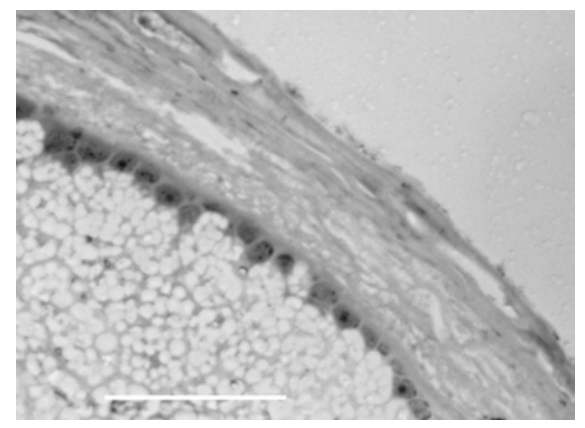

Fig. 4. Sureno (LM). Scale bar $=75 \mu \mathrm{m}$. 